\title{
Human angiopoietin gene expression is a marker for severity of pulmonary hypertension in patients undergoing pulmonary thromboendarterectomy
}

Patricia A. Thistlethwaite, $\mathrm{MD}, \mathrm{PhD}^{\mathrm{a}}$

Sang H. Lee, $M D^{a}$

Ling-Ling $\mathrm{Du}, \mathrm{MD}^{\mathrm{a}}$

Paul L. Wolf, MD

Christopher Sullivan, $\mathrm{MS}^{\mathrm{a}}$

Sujit Pradhan, BS ${ }^{a}$

Renna Deutsch, $\mathrm{PhD}^{\mathrm{C}}$

Stuart W. Jamieson, MB, FRCS ${ }^{a}$
From the Division of Cardiothoracic Surgery, University of California, San Diego, ${ }^{\text {a }}$ the Department of Pathology, Veterans Affairs Medical Center, ${ }^{\mathrm{b}}$ and the Department of Family and Preventive Medicine, University of California, San Diego, Calif. ${ }^{\mathrm{c}}$

This study was supported in part by the Maurice and Charmaine Kaplan Foundation (Patricia A. Thistlethwaite, MD, PhD) and the Thoracic Surgery Foundation Research Fellowship (Sang H. Lee, MD)

Read at the Eightieth Annual Meeting of The American Association for Thoracic Surgery, Toronto, Ontario, Canada, April 30-May 3, 2000.

Received for publication Aug 8, 2000; revisions requested Sept 27, 2000; revisions received Nov 29, 2000; accepted for publication Dec 1, 2000.

Address for reprints: Patricia A Thistlethwaite, MD, PhD, Assistant Professor of Surgery, Cardiothoracic Surgery, University of California, San Diego, 200 West Arbor Dr, San Diego, CA 92103 8892 (E-mail: pthistlethwaite@ucsd.edu).

J Thorac Cardiovasc Surg 2001;122:65-73 12/6/113753

doi:10.1067/mtc.2001.113753
Objective: A consistent pathologic feature seen in lungs of patients with pulmonary hypertension from thromboembolic disease is hyperplasia of the media of pulmonary arterioles. The molecular factors responsible for these vessel wall changes are unknown. Angiopoietin-1 is a gene responsible for the formation of the media of blood vessels in utero. We hypothesized that aberrant expression of the angiopoietin-1 gene in the adult lung would be a major contributing factor in the development of pulmonary hypertension.

Methods: From April 1999 to March 2000, a total of 35 patients (18 men, 17 women, mean age 52 years) with pulmonary hypertension and pulmonary vascular resistance ranging from 407 to 2006 dynes $\cdot \mathrm{sec} \cdot \mathrm{cm}^{-5}$ underwent pulmonary endarterectomy at our institution. Before cardiopulmonary bypass, lung biopsy specimens were taken from each patient. Biopsy specimens were also obtained from 10 patients ( 5 women, 5 men, mean age 55 years) undergoing lung resection for causes other than pulmonary hypertension. All specimens were blindly scored by a pathologist for degree of medial hyperplasia. Quantitative reverse transcriptase-polymerase chain reaction, Western blot, and immunohistochemistry were used to quantitate angiopoietin-1 messenger RNA and protein in each sample.

Results: Lung specimens from all patients with pulmonary hypertension demonstrated up-regulation of angiopoietin-1 at the messenger RNA level. The degree of angiopoietin-1 transcription was directly proportional to the preoperative pulmonary vascular resistance and medial wall hyperplasia/hypertrophy in each patient. By immunohistochemistry, angiopoietin-1 protein was confined to the media of pulmonary arterioles. Lung biopsy specimens from patients without pulmonary hypertension had no detectable expression of angiopoietin- 1 at the messenger RNA or protein level.

Conclusion: Angiopoietin-1, a gene responsible for vessel development in the embryonic lung, is up-regulated in the lung parenchyma of patients with pulmonary hypertension. The level of expression of angiopoietin-1 at messenger RNA and protein levels correlates to the severity of pulmonary hypertension in patients with thromboembolic disease and serves as a target for strategies to treat this disease. 


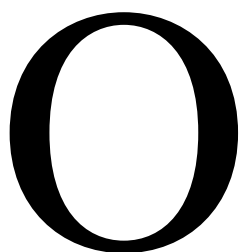

ne of the major pathologic features of chronic pulmonary hypertension is muscular hypertrophy and hyperplasia of small pulmonary arterioles and capillaries. This process is progressive, diffuse, and eventually results in obliteration of the distal pulmonary arterial tree. Muscularization of small pulmonary vessels occurs in all forms of pulmonary hypertension, including primary idiopathic disease as well as that induced by thromboembolism, drugs, or pulmonary shunt. ${ }^{1}$ Although this pathologic condition is seen in both adults and children with pulmonary hypertension, the mechanism of this vasculopathy is unknown.

Pulmonary hypertension develops in patients with significant chronic thromboembolic disease of the lung. ${ }^{2}$ At the microscopic level, the pulmonary vasculature of these patients reveals two distinct pathologic processes. The proximal pulmonary artery tree contains focal macroscopic organized thrombus and pronounced intimal thickening, and the distal pulmonary tree contains small-vessel muscular hypertrophy and hyperplasia. ${ }^{3}$ Complete surgical removal of the proximal thrombus and intimal thickening in the proximal pulmonary arterial tree by endarterectomy achieves normalization of pulmonary arterial pressures and arrests the distal small-vessel vasculopathy. ${ }^{4}$

Establishment and muscular remodeling of blood vessels is regulated by paracrine signals between endothelial and smooth muscle cells. ${ }^{5}$ Angiopoietin-1 (Ang-1), a 70-kd secreted peptide, is an angiogenic factor essential for normal lung vascular development. Produced by smooth muscle cells and smooth muscle cell precursor pericytes, Ang-1 functions to stabilize blood vessel development by recruiting muscle cells, through migration and division, to nascent endothelial tubes, creating mature arterial structures. ${ }^{6}$ Animals deficient in Ang-1 by null mutation die in utero with little arterial development in the lung and other organs. ${ }^{7}$ The two receptors for Ang-1, TIE1 and TIE2, are present only on vascular endothelium. The ligand-receptor interaction between smooth muscle cell-secreted Ang-1 and the endothelium-specific TIE receptors in organ development induces proliferation of smooth muscle cells around the growing endothelial vascular network. ${ }^{8}$ After pulmonary development and maturation are completed, Ang-1 is not expressed in the human lung.

Since pulmonary hypertension is a disease of excessive muscular investment of pulmonary capillaries and arterioles, we hypothesized that this process may be due to aberrant expression of Ang-1 gene product. To evaluate the role of Ang-1 in pulmonary hypertension, we examined lung tissue from patients with this disease undergoing pulmonary endarterectomy at our institution for deregulation of Ang-1 gene and protein expression.

\section{Methods}

\section{Patient Selection}

Between April 1999 and March 2000, 45 patients (22 men and 23 women; mean age 53.5 years; range $27-73$ years) undergoing either pulmonary endarterectomy or pulmonary resection were enrolled in this study. Thirty-five of the patients underwent pulmonary endarterectomy for end-stage pulmonary hypertension (mean pulmonary vascular resistance [PVR] 717 dynes $\cdot$ sec . $\mathrm{cm}^{-5}$; range 407-2006 dynes $\cdot \mathrm{sec} \cdot \mathrm{cm}^{-5}$ ). Ten control patients with normal PVR underwent wedge resection of the lung for benign pulmonary nodules (mean PVR 177.5 dynes $\cdot \mathrm{sec} \cdot \mathrm{cm}^{-5}$; range 145-210 dynes $\cdot \mathrm{sec} \cdot \mathrm{cm}^{-5}$ ). According to the usual practice at our institution, pulmonary hypertension was defined as PVR greater than 300 dynes $\cdot \mathrm{sec} \cdot \mathrm{cm}^{-5}$ and pulmonary artery systolic pressure greater than $50 \mathrm{~mm} \mathrm{Hg} .{ }^{9}$

The selection criteria for patients undergoing pulmonary endarterectomy included the following: (1) New York Heart Association class III or IV, (2) PVR greater than 300 dynes $\cdot$ sec $\mathrm{cm}^{-5}$, (3) absence of significant comorbid disease unrelated to right-sided heart failure, and (4) the appearance of chronic thrombi on angiography. ${ }^{10}$ All patients enrolled in this study were between 35 and 80 years of age and had given written informed consent for lung biopsy. The study was approved by the University of California, San Diego, Institutional Review Board.

\section{Biopsy of Lung}

After induction of anesthesia and either median sternotomy (for pulmonary endarterectomy) or thoracotomy (for lung resection), the lung of each patient was examined and a 4-cm biopsy specimen was taken with the use of a GIA tissue stapler (United States Surgical Corporation, Auto Suture Company Division, Norwalk, Conn). For patients undergoing pulmonary endarterectomy, the biopsy tissue was taken from a segment of lung most involved with pulmonary occlusive disease according to preoperative angiography. Specimens were taken before cardiopulmonary bypass and during ventilation with an inspired oxygen fraction $\left(\mathrm{FIO}_{2}\right)$ of $100 \%$ and peripheral oxygen saturations of greater than $95 \%$. Specimens from patients with benign lung nodules were taken before anatomic resection and during ventilation with an $\mathrm{FIO}_{2}$ of $100 \%$ and peripheral oxygen saturations of greater than $95 \%$.

\section{Sample Preparation and Extraction of RNA and Protein}

One third of each biopsy specimen was fixed in formalin, sectioned to a thickness of $5 \mu \mathrm{m}$, mounted on a slide, and stained with hematoxylin and eosin. The mounted specimens were examined by light microscopy to quantitate the pathologic severity of pulmonary hypertension in each sample. The remaining lung specimens were frozen in liquid nitrogen at $-140^{\circ} \mathrm{C}$ and later processed for RNA and protein extraction.

For total RNA isolation, portions of the frozen samples were lyophilized, and then RNA was extracted by means of the acid guanidinium thiocyanate-phenol-chloroform technique, as previously described. ${ }^{11,12}$ The recovered RNA pellet was dried under vacuum conditions for 10 minutes and then dissolved in diethyl pyrocarbonate-treated deionized distilled water. The concentration 
and purity of the RNA were determined by spectrophotometric analysis (Ultro-spec II, Biochrom, Cambridge, United Kingdom) at 260 and $280 \mathrm{~nm}$. The samples were stored at $-80^{\circ} \mathrm{C}$ until analyzed.

For protein isolation, portions of the frozen lung samples were prepared for protein purification as previously described. ${ }^{13}$ Portions of each recovered protein extract were tested in a Bradford Protein Assay (Bio-Rad Microscience, Hercules, Calif) to determine total protein concentration of each sample. Protein extracts were used fresh or stored at $-80^{\circ} \mathrm{C}$ until used. ${ }^{14}$

\section{Measurement of Ang-1 Messenger RNA (mRNA)}

The reverse-transcriptase polymerase chain reaction (RT-PCR) was used to analyze each lung specimen for the presence of transcripts encoding Ang-1 and glyceraldehyde-3-phosphate dehydrogenase (GAPDH). GAPDH mRNA was studied as a marker to control for variation in RNA concentration and RNA degradation as potential confounding variables. Total RNA $(5 \mu \mathrm{g})$ was used to synthesize complementary DNA (cDNA) with SuperScript II Reverse Transcriptase and oligo (dT) ${ }^{12-18}$ (Gibco BRL, Life Technologies, Inc, Rockville, Md). The synthesized primers had the following sequences: for Ang-1, 5' GGCAACTGTCGTGAGAGTACGA 3' and 5' ATTTAGATTGGAGGGGCCACA 3' (Gibco BRL); for GAPDH, 5' CATCATCTCTGCCCCCTC TG 3' and 5' CCTGCTTCACCACCTTCTTG 3’'(Genbase Inc, San Diego, Calif).

Duplicate amplification reactions were carried out with a single block thermocycler (Ericomp Inc, San Diego, Calif) containing 0.2 $\mu \mathrm{mol} / \mathrm{L}$ of each primer, deoxynucleotide triphosphates $(200$ $\mathrm{mmol} / \mathrm{L}$ each), $1.5 \mathrm{mmol} / \mathrm{L}$ magnesium chloride, 0.5 unit of Taq DNA polymerase, and $36.5 \mu \mathrm{L}$ of autoclaved distilled water. Each sample underwent initial denaturation at $94^{\circ} \mathrm{C}$ for 5 minutes, 38 cycles of denaturation at $94^{\circ} \mathrm{C}$ for 1 minute, annealing at $62^{\circ} \mathrm{C}$ for 2 minutes, extension at $72^{\circ} \mathrm{C}$ for 2 minutes, and a final extension at $72^{\circ} \mathrm{C}$ for 10 minutes. The PCR products were electrophoresed on a $1 \%$ agarose gel containing $0.2 \mu \mathrm{g} / \mathrm{mL}$ ethidium bromide in Tris-acetate-ethylenediaminetetraacetic acid buffer. The gels were photographed with a digital electrophoresis photodocumentation camera (Fisher Scientific, Pittsburgh, Pa).

Quantitative comparative PCR methods were used to quantitate steady-state levels of Ang-1 transcripts. ${ }^{15}$ PCR amplifications for Ang-1 and GAPDH were performed on lung specimens that demonstrated Ang-1 transcripts on nonquantitative PCR analysis. Ang-1 and GAPDH were synthesized in the conditions described above, but were removed at specific cycle numbers of 16, 20, 24, $28,32,36$, and 40 . These products were electrophoresed on $1 \%$ agarose gels. The resulting bands were digitally photographed and quantitated for density using the IS-1000 digital imaging system (Alpha Innotech Corporation, San Leandro, Calif). For each sample amplification series, the densities in pixels were digitally plotted versus cycle number. By this method the linear and plateau phases were noted to be at 24 and 32 cycles, respectively. For each sample, the densities of Ang-1 products were compared with the densities of GAPDH products, with GAPDH serving as an internal standard control. The ratio of Ang-1 product to GAPDH product at cycle 24 (linear phase) was obtained by dividing Ang-1 band density by GAPDH band density.

\section{Measurement of Ang-1 Protein}

Western blot analysis was performed with the use of a previously described protocol. ${ }^{16}$ In brief, $10 \mu \mathrm{g}$ of each protein extract was diluted with an equal volume of $2 \times$ SDS sample buffer (Novex, San Diego, Calif). Samples were loaded into a $4 \%$ to $20 \%$ TG-gel (Novex) in equal protein concentrations and electrophoresed at 60 to 100 volts for 5 hours. The gel products were transferred at 22 volts for 12 hours at $4^{\circ} \mathrm{C}$ to a nitrocellulose membrane using the Novex-Cell II apparatus (Novex). The nitrocellulose was incubated in washing buffer $(10 \mathrm{mmol} / \mathrm{L}$ Tris- $\mathrm{HCl}$ at $\mathrm{pH} 8.0,150 \mathrm{mmol} / \mathrm{L}$ $\mathrm{NaCl}, 0.2 \%$ gelatin, $0.05 \%$ Tween- $20,0.2 \%$ bovine serum albumin). Blocking was performed by means of $3 \%$ bovine serum albumin washing buffer for 1 hour at room temperature. The nitrocellulose was then cleaned with washing buffer for 5 minutes.

Subsequently, the primary antibody, goat polyclonal immunoglobulin G (IgG) anti-human Ang-1 (Santa Cruz Biotechnology, Santa Cruz, Calif) at 1:500 dilution in 3\% bovine serum albumin washing buffer, was added for overnight binding at $4^{\circ} \mathrm{C}$. The nitrocellulose was then incubated in washing buffer for 3 cycles of 5 minutes each. The secondary antibody, anti-goat IgG alkaline phosphatase (Santa Cruz Biotechnology), diluted 1:1000, was incubated with the nitrocellulose membrane for 1 hour at room temperature. The membrane was then bathed in washing buffer for 3 cycles of 5 minutes each, then placed into substrate solution (100 $\mathrm{mmol} / \mathrm{L}$ Tris- $\mathrm{HCl}, 100 \mathrm{mmol} / \mathrm{L} \mathrm{NaCl}, 5 \mathrm{mmol} / \mathrm{L} \mathrm{MgCl}_{2}$ at $\mathrm{pH} 9.5$, $165 \mu \mathrm{g} / \mathrm{mL}$ 5-bromo-4 chloro-3-indolyl-phosphate, $330 \mu \mathrm{g} / \mathrm{mL}$ nitro blue tetrazolium) until protein bands were visible. The filters were then placed in distilled water, dried, and imaged using a digital scanner (Hewlett-Packard ScanJet, Palo Alto, Calif).

The same procedure was performed for actin, which acted as an internal control, using mouse anti-human actin IgG primary mouse monoclonal antibody (Santa Cruz Biotechnology) at 1:3000 dilution and goat anti-mouse $\operatorname{IgG}(\mathrm{H}+\mathrm{L})$ alkaline phosphatase (Southern Biotechnology Associates, Birmingham, Ala) at 1:1000 dilution.

\section{Immunohistochemical Staining for Ang-1}

Portions of the frozen biopsy specimens were fixed in $10 \%$ formalin and prepared as $5-\mu \mathrm{m}$ thick tissue sections on slides. The paraffin was then removed with a xylene substitute (Hemo-De; Fisher Scientific, Pittsburgh, Pa) and the sections were rehydrated with ethanol gradient washes. The sections were incubated with goat anti-human Ang-1 polyclonal IgG (Santa Cruz Biotechnology) at a 1:100 dilution. Control sections were incubated with diluted normal goat serum (Vector Laboratories, Burlingame, Calif) in lieu of primary antibody. All sections were subsequently incubated with biotinylated secondary anti-goat antibodies and stained with an immunoperoxidase technique (Vectastain Elite $\mathrm{ABC}$ reagents, Vector Laboratories). Sections were dried and mounted (Gel Mount; Biomeda Corp, Foster City, Calif), examined with a photomicroscope, and photographed on color film (Fujicolor 100; Fuji Photo Film Co, Tokyo, Japan).

\section{Statistical Analysis}

The 35 patients undergoing pulmonary endarterectomy and 10 control patients were compared according to preoperative medical 




Figure 1. Pathologic changes in representative lung biopsy specimens (hematoxylin and eosin stain, $\times 400$ ). Normal pulmonary arteriolar structure is seen in a patient without pulmonary hypertension (A), medial arteriolar hyperplasia/ hypertrophy in a patient with a PVR of 655 dynes $\cdot \sec \cdot \mathrm{cm}^{-5}(\mathrm{~B})$, and obliteration of pulmonary arteriolar lumen by smooth muscle cell deposition in a patient with a PVR of 1541 dynes $\cdot \sec \cdot \mathrm{cm}^{-5}$ (C).

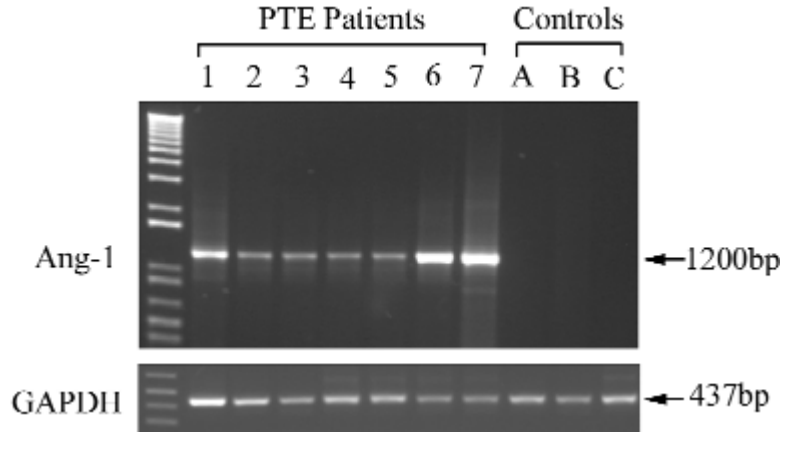

Figure 2. Results of analysis of lung biopsy tissue by the PCR. Lung specimens 1 to 7 were taken from patients with a PVR greater than 500 dynes $\cdot$ sec $\cdot \mathbf{c m}^{-5}$. Lung specimens $A$ to $C$ were taken from patients with a PVR less than 210 dynes $\cdot \mathbf{s e c} \cdot \mathrm{cm}^{-5}$. Transcript lengths detected are shown on the right. PTE, Pulmonary thromboendarterectomy; bp, base pair.

variables by means of a Student independent group $t$ test for normally distributed variables and Wilcoxon rank sum test for those measures that were not normal. Gender between the pulmonary endarterectomy and control cohorts was compared by means of a Fisher exact test. Group mean and standard deviation or median (range) are reported for each normal and non-normal variable, respectively. Sex for each group is shown as sample size (proportion male).

\section{Results}

All lung biopsy specimens were examined by light microscopy to quantitate pulmonary hypertensive changes according to the Heath-Edwards classification ${ }^{17}$ by a lung pathologist who was unaware of the patient's identity. Each of the 35 specimens taken from patients undergoing pulmonary endarterectomy demonstrated Heath-Edwards stage 2 to 5 disease with diffuse medial arteriolar hypertrophy/ hyperplasia and stenosis of at least one third of all viewed capillaries/arterioles. The 10 specimens taken from patients without pulmonary hypertension demonstrated normal lung histologic characteristics or scattered bullous emphysema. A direct correlation existed between preoperative clinical variables (pulmonary artery pressures, PVR) and the pathologic classification of each affected specimen. Figure 1 shows representative biopsy abnormalities from the 2 groups of patients.

The characteristics, cardiac indices, and pulmonary function measurements of the patients before operation and lung biopsy are shown in Table 1 . The pulmonary endarterectomy patients and controls were similar with respect to age, sex, arterial oxygen tension, $\mathrm{FIO}_{2}$, pulmonary capillary wedge pressure, cardiac output, single-breath diffusing capacity for carbon monoxide, forced expiratory volume in 
TABLE 1. Preoperative clinical variables*

\begin{tabular}{|c|c|c|c|}
\hline & PTE patients & Controls & $P$ value \\
\hline Total patients & 35 & 10 & \\
\hline Male & $17(49 \%)$ & $5(50 \%)$ & 1.00 \\
\hline Age (y) & $52 \pm 30.5$ & $55 \pm 25.7$ & .36 \\
\hline $\mathrm{PaO}_{2}(\mathrm{~mm} \mathrm{Hg})$ & $296.7 \pm 110.8$ & $270.5 \pm 63.5$ & .48 \\
\hline $\mathrm{FlO}_{2}(\%)$ & $100 \pm 0$ & $100 \pm 0$ & - \\
\hline PA systolic (mm Hg) & $83.2 \pm 16.3$ & $30.7 \pm 9.1$ & .0001 \\
\hline PA diastolic (mm Hg) & $36.3 \pm 9.4$ & $13.0 \pm 7.0$ & .0001 \\
\hline PVR (dynes $\cdot \mathrm{sec} \cdot \mathrm{cm}^{-5}$ ) $\dagger$ & $717.0(407,2006)$ & $177.5(145,210)$ & .0001 \\
\hline PCW (mm Hg)† & $10.0(6,15)$ & $9(5,14)$ & .53 \\
\hline CO (L/min) & $3.27 \pm 0.8$ & $3.6 \pm 0.8$ & .31 \\
\hline $\mathrm{FEV}_{1}(\%$ predicted $)$ & $69 \pm 11.8$ & $66 \pm 14.1$ & .68 \\
\hline DLCO & $71.4 \pm 16.2$ & $67.7 \pm 16.7$ & .53 \\
\hline Hematocrit & $38.5 \pm 4.1$ & $38.8 \pm 3.2$ & .84 \\
\hline
\end{tabular}

1 second, and hematocrit. The pulmonary endarterectomy group had significantly higher pulmonary artery systolic and diastolic pressures and PVR compared to the control group $(P<.0001)$. No inferential statistical comparison was made for $\mathrm{FIO}_{2}$ because an $\mathrm{FIO}_{2}$ of $100 \%$ was used in all subjects in both groups at the time of biopsy.

\section{Molecular Analysis of Lung Specimens}

Figure 2 shows the results of nonquantitative PCR analysis of samples of RNA from lung specimens from the 2 groups of patients. The 35 patients with pulmonary hypertension undergoing pulmonary endarterectomy had detectable steady-state levels of Ang-1 mRNA in their lung biopsy tissue. Ang-1 transcripts were not detected in any biopsy specimens from patients with a PVR less than 300 dynes $\cdot \mathrm{sec} \cdot \mathrm{cm}^{-5}$. The Ang-1 mRNA detected in all the affected specimens was 1200 base pairs long. This Ang-1 transcript corresponds to the known 70-kd Ang-1 protein. We found that levels of GAPDH mRNA were consistently equal among the samples studied.

Patients with a higher preoperative PVR had greater amounts of steady-state Ang-1 mRNA in the lung as assayed by semiquantitative PCR analysis. Indeed, the degree of Ang-1 gene expression correlated directly with the severity of pulmonary hypertension as measured by the preoperative PVR and pulmonary artery pressure. Figure 3 shows the results of semiquantitative PCR using mRNA from 3 patients with varying severities of pulmonary hypertension. GAPDH served as an internal control to establish relative band density ratios in these patients. We found this direct correlation between gene expression and phenotype (elevated PVR) in all patient samples studied. Ang-1 mRNA was not detected by quantitative PCR analysis in the peripheral blood or main pulmonary artery wall of patients (data not shown), suggesting this protein and its effect are confined to the lung.

\section{Quantitation and Localization of Ang-1 Protein in Pulmonary Endarterectomy Lung Specimens}

By Western blot analysis, Ang-1 protein was detected in the lungs of all patients with pulmonary hypertension and was not present in biopsy specimens of patients undergoing lung resection for benign causes (Figure 4). The Ang-1 protein was detected as a 70-kd peptide, corresponding to the known weight of this moiety in human beings. Patients with a higher preoperative PVR had increased levels of Ang-1 protein in their lung biopsy specimens as compared with lung tissue taken from patients with a normal PVR. The magnitude of Ang-1 protein present for a given lung specimen directly correlated with the severity of the preoperative PVR (Figure 5), as well as the degree of pulmonary hypertensive changes identified by pathologic analysis. Actin protein was concomitantly measured in each protein sample to ensure against confounding variables such as protein degradation or variation in protein concentration. Actin protein was consistently equal in amount among all samples studied.

Immunohistochemical staining with antibody to Ang-1 of sectioned biopsy specimens from patients with elevated PVR revealed that Ang-1 protein was confined to the media of pulmonary arterioles and small muscular arteries measuring less than $500 \mu \mathrm{m}$ in size (Figure 6). Immunoreactivity was identified in the cytoplasm of smooth muscle cells lining these small 


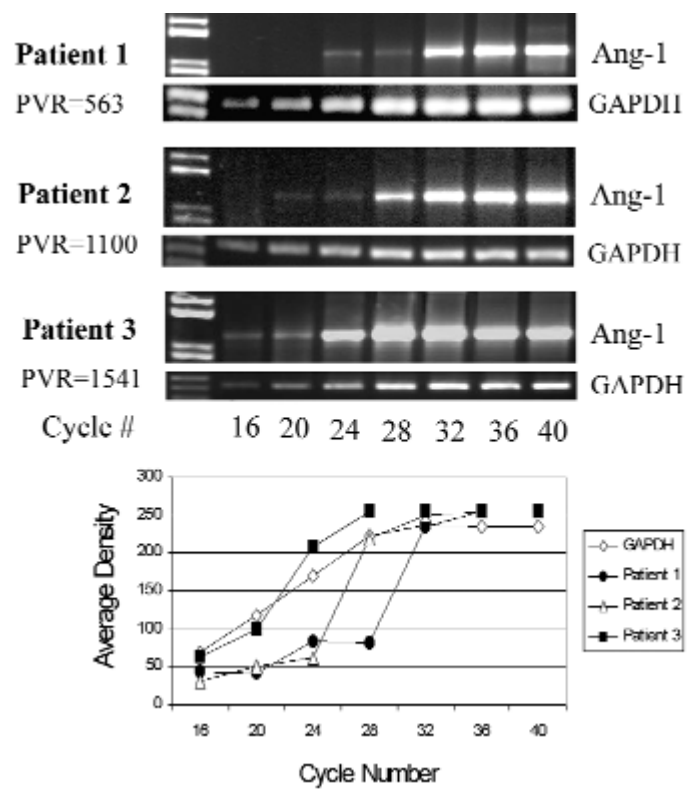

Figure 3. Quantitative comparative RT-PCR of Ang-1 mRNA in 3 patients with ranging degrees of PVR. Ratio reflects Ang-1 band density divided by standard GAPDH band density at linear cycle 24.

lung vessels (Figure 7). Ang-1 protein was not detected in alveolar parenchyma, large pulmonary arteries, or pulmonary veins. Ang-1 protein was not detected by immunohistochemical staining in the lungs of patients with normal PVR.

\section{Discussion}

The genesis of pulmonary hypertension is a complex vascular process involving alterations in vessel wall anatomy in the lung. In the early phases of pulmonary hypertension, the distal pulmonary vasculature is morphologically normal but capable of exaggerated vasoconstriction. ${ }^{18}$ As the disease progresses, clear-cut morphologic changes in the distal pulmonary arterioles occur, resulting in muscular hyperplasia and hypertrophy of the medial layer of these vessels. ${ }^{19}$ This vessel wall thickening obstructs arteriolar blood flow and eventually results in obliteration of the distal pulmonary arterial tree. ${ }^{20}$ Although mechanisms of increased pulmonary blood flow, hypoxia, and increased pulmonary arterial bed pressures have been speculated to be triggers of this vasculopathy, little is known about the molecular signals that generate this process. Administration of epoprostenol (prostacyclin) analogs or nitric oxide to patients with pulmonary hypertension is known to attenuate the vasoreactive component of the disease but has made little impact in arresting the resultant pulmonary arteriolar hyperplasia and hypertrophy, which ultimately destroy the lung and lead to right-sided heart failure. ${ }^{21,22}$

One of the more common causes of pulmonary hypertension in adults is chronic thromboembolism to the lung. In

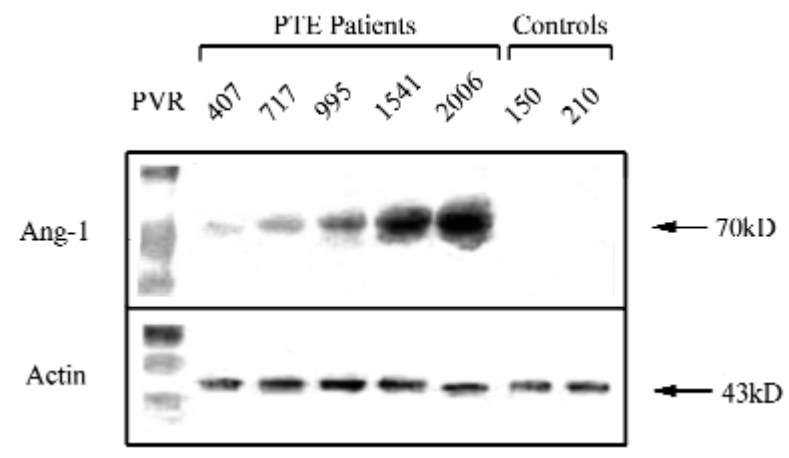

Figure 4. Western blot quantitation of Ang-1 protein. The molecular weights of Ang-1 and actin proteins detected are shown on the right in kilodaltons (kD). PTE, Pulmonary thromboendarterectomy.

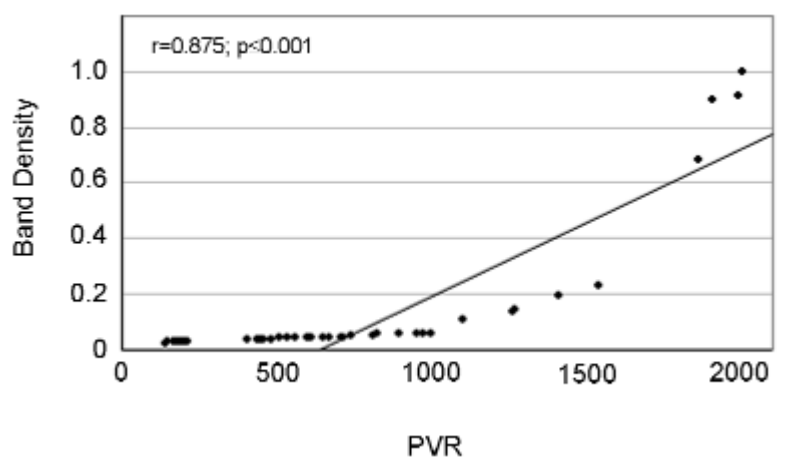

Figure 5. Linear regression analysis demonstrating correlation between Ang-1 protein expression in the lung to degree of preoperative PVR in 45 patients. The $Y$ axis denotes Western blot band densities of Ang-1 normalized to actin. The $X$ axis denotes PVR (dynes $\cdot \mathbf{s e c} \cdot \mathrm{cm}^{-5}$ ).

selected patients, pulmonary endarterectomy is an effective modality for treating proximal thromboembolic disease in the pulmonary artery tree. ${ }^{23}$ Our institution performs more than 100 pulmonary endarterectomies a year for thromboembolic pulmonary hypertension. ${ }^{24}$ This patient population represents a major resource for the clinical and basic science study of this disease. Pulmonary endarterectomy treats two disease processes in the lung. First, by direct surgical manipulation, organized thrombus and fibrotic thickening in the intima of the first few divisions of the pulmonary tree are removed. Second, this equalization of blood flow throughout the lung arrests the progression of distal arteriolar vasculopathy. By pathologic analysis, we have found that the small-vessel medial hyperplastic and hypertrophic response occurs throughout the lung, irrespective to the lobar or segmental artery affected by the thromboembolic disease. 


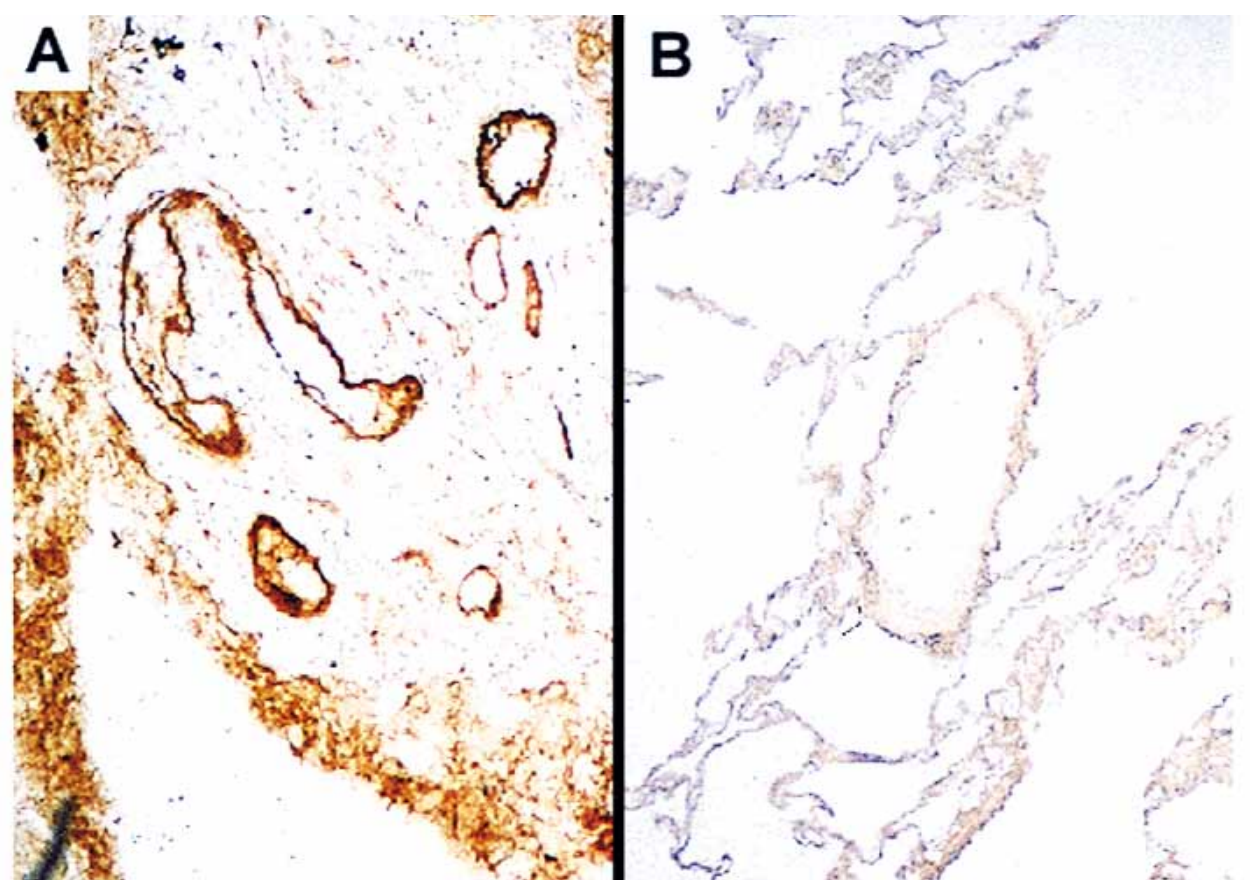

Figure 6. Localization of Ang-1 protein in lung biopsy specimens (immunohistochemical staining $\times 200$ ). Immunohistochemical analysis with antibody to Ang-1 on lung was obtained from a patient with a PVR of 960 dynes - sec . $\mathrm{cm}^{-5}(\mathrm{~A})$ and a patient with a PVR of 185 dynes $\cdot \sec \cdot \mathrm{cm}^{-5}$ (B).

The goal of this study was to examine specimens of human lung tissue affected by thromboembolic pulmonary hypertension and to correlate the physiologic and pathologic state of the lung with the degree of expression of Ang-1. Our results show that Ang-1 is a quantitative marker for pulmonary hypertension and PVR in the lung. The normal adult lung does not express Ang-1 at the RNA or protein level. In contrast, Ang-1 is expressed in the wall of small pulmonary arteries and arterioles less than $500 \mu \mathrm{m}$ in diameter in patients with pulmonary hypertension. The degree of Ang-1 expression at both RNA and protein levels in the lung is directly proportional to the magnitude of PVR. Thus, in patients with thromboembolic disease, the Ang-1 gene product is a sensitive molecular marker for the severity of pulmonary hypertension. Although Ang-1 expression was associated with the magnitude of preoperative PVR, we cannot conclude from this study alone whether this change in gene expression was causal or secondary to the development of pulmonary hypertension.

Ang-1 is a smooth muscle mitogen and growth factor in the developing lung. ${ }^{25}$ This moiety, first isolated in 1996 by Davis and associates, ${ }^{26}$ plays a critical role in embryonic vascular network maturation and remodeling by recruiting muscle cells to newly formed endothelial tubes. It is a member of a 4-gene family (Ang-1, Ang-2, Ang-3, and Ang-4), each of which is a ligand for endothelium-based tyrosine kinase membrane receptor TIE2 and its related receptor
TIE1. Ang-2 is a naturally occurring antagonist of Ang-1 and in adult mice is expressed only at sites of vascular remodeling such as the skin, endometrium, and placenta. ${ }^{27}$ Its role in the human lung is unknown. Ang-3 and Ang-4 have recently been cloned by sequence homology, and their physiologic importance and pattern of expression are unknown. ${ }^{28}$ Ang-1, in contrast, is responsible for recruiting and sustaining periendothelial support (muscle) cells in the maturation and stabilization of the developing neovasculature. ${ }^{29}$ In addition to its role as a muscular growth factor and mitogen, Ang-1 has also been shown to up-regulate the apoptosis inhibitor, survivin, in endothelial cells, through the serine threonine kinase pathway, Akt, thereby protecting endothelium from programmed cell death. ${ }^{30}$ Targeted disruption of the gene encoding Ang-1 causes embryonic lethality with severe vascular abnormalities in the developing mouse. ${ }^{7}$ Mice rendered null homozygous for Ang-1 have immature cardiac, great vessel, and lung development with minimal arterial structures forming in these organs. The lungs of these mutant mice contain venous lake structures, and vessels lack smooth muscle media investment. The expression of Ang-1 is thus critical to the development of a mature pulmonary arterial tree with vessels composed of intimal, medial, and adventitial layers.

Two important limitations of this study should be recognized. First, because we used the PCR technique to detect steady-state levels of Ang-1, our study did not distinguish 


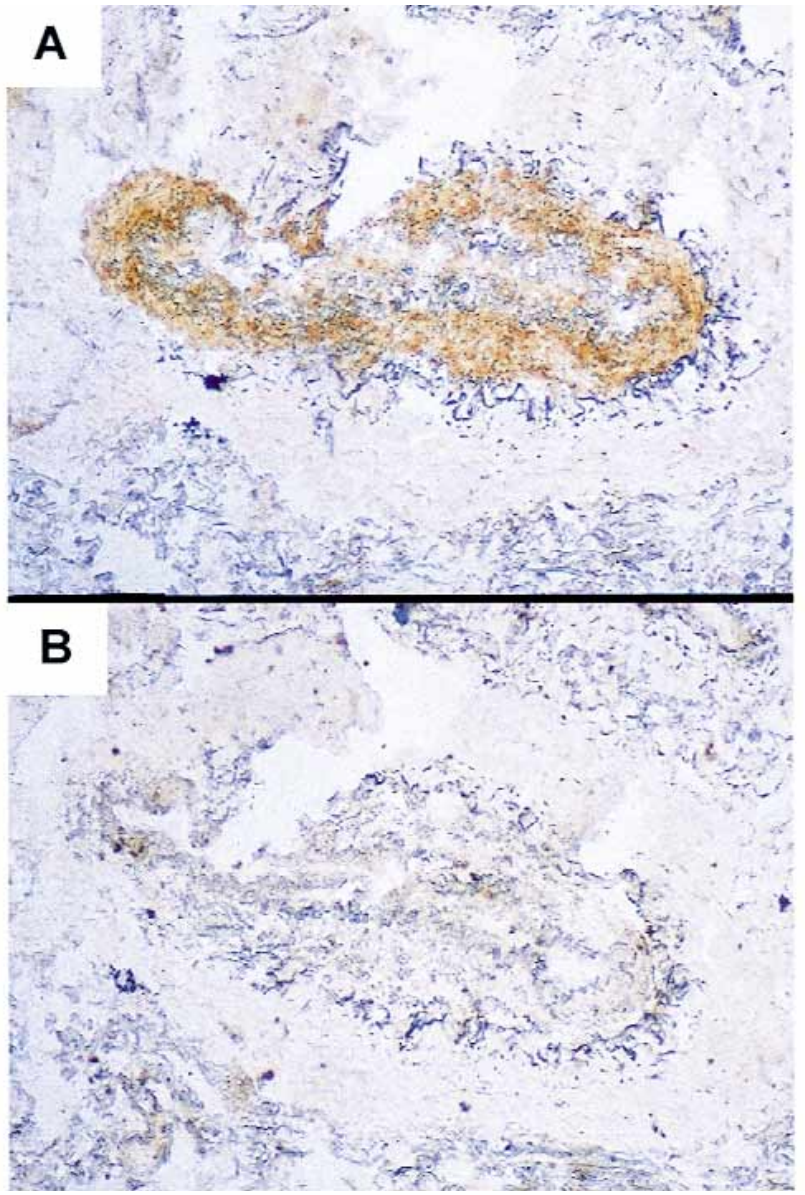

Figure 7. Cytoplasmic localization of Ang-1 protein in smooth muscle cells in pulmonary arterioles by immunohistochemical staining (magnification $\times 400$ ). A, With antibody to Ang-1. B, Without antibody to Ang-1.

whether the accumulation of Ang-1 mRNA in the lung reflected enhanced transcription or enhanced stabilization of mRNA. Second, because our study examined specimens from human subjects, it was necessarily limited in scope and time course. Despite our inability to perform serial biopsies in individual patients during the progression of pulmonary hypertension, we found clear evidence that the degree of Ang1 expression in the lung at RNA and protein levels parallels the severity of PVR and degree of pulmonary arteriolar medial thickening. Our results suggest that Ang-1 may be a signal mechanism for vascular muscle cell hypertrophy and hyperplasia in the lung. Further understanding of the effects of Ang- 1 in the pulmonary artery tree may reveal clues for treating pulmonary hypertension and modulating vascular wall biology in this organ system.

We thank Angela Ramsey for assistance in the preparation of the manuscript.

\section{References}

1. Katzenstein ALA, Askin FB. Pulmonary hypertension and other vascular disorders. In: Bennington JL, editor. Surgical pathology of nonneoplastic lung disease. Vol 13. Philadelphia: WB Saunders; 1982. p. 283-92.

2. Paraskos JA, Adelstein SJ, Smith RE, Rickman FD, Grossman W, Dexter L, et al. Late prognosis of acute pulmonary embolism. $N$ Engl J Med. 1973;289:55-8.

3. Kapitan KS, Buchbinder M, Wagner PD, Moser KM. Mechanisms of hypoxemia in chronic thromboembolic pulmonary hypertension. Am Rev Respir Dis. 1989;139:1149-54.

4. Tanabe N, Okada O, Nakagawa Y, Masuda M, Kato K, Nakajima N, et al. The efficacy of pulmonary thromboendarterectomy on long-term gas exchange. Eur Respir J. 1997;10:2066-72.

5. Folkman J, D'Amore PA. Blood vessel formation: What is its molecular basis? Cell. 1998;87:1153-5.

6. Papapetropoulos A, Garcia-Cardena G, Dengler TJ, Maisonpierre PC, Yancopoulos GD, Sessa WC. Direct actions of angiopoietin-1 on human endothelium: evidence for network stabilization, cell survival, and interaction with other angiogenic growth factors. Lab Invest. 1999;79:213-23.

7. Suri C, Jones PF, Patna S, Burtunkova S, Maisonpierre PC, Davis S, et al. Requisite role of angiopoietin-1, a ligand for the TIE2 receptor, during embryonic angiogenesis. Cell. 1996;87:1171-80.

8. Hanahan D. Signaling vascular morphogenesis and maintenance. Science. 1997;277:48-50.

9. Archibald CJ, Auger WR, Fedullo PF, Channick RN, Kerr KM, Jamieson SW, et al. Long-term outcome after pulmonary thromboendarterectomy. Am J Respir Crit Care Med. 1999;160:523-8.

10. Moser KM, Fedullo PF, Auger WR, Channick RW. Criteria for pulmonary thromboendarterectomy. Chest. 1995;108:1767-8.

11. Chomczynski P, Sacchi N. Single-step method of RNA isolation by acid guanidinium thiocyanate-phenol-chloroform extraction. Anal Biochem. 1987;162:156-9.

12. Puissant C, Houdebine LM. An improvement of the single-step method of RNA isolation by acid guanidinium thiocyanate-phenolchloroform extraction. Biotechniques. 1990;8:148-9.

13. Sambrook J, Fritsch EF, Maniatis T. Detection and analysis of proteins expressed from cloned genes. In: Ford N, Nolan C, Ferguson M, editors. Molecular cloning: a laboratory manual. Vol 3, 2nd ed. Plainview, NY: Cold Spring Harbor Laboratory Press; 1989. p. 18.61-3.

14. Bradford MM. A rapid and sensitive method for the quantitation of microgram quantities of protein utilizing the principle of protein-dye binding. Anal Biochem. 1976;72:248-54.

15. Hirst WD, Young KA, Newton R, Allport VC, Marriott DR, Wilkin GP. Expression of COX-2 by normal and reactive astrocytes in the adult rat central nervous system. Mol Cell Neurosci. 1999;13:57-68.

16. Bardoff C, Lee GH, Lamphear BJ, Martone ME, Campbell KP, Rhoads RE, et al. Enteroviral protease 2A cleaves dystrophin: evidence of cytoskeletal disruption in an acquired cardiomyopathy. Nat Med. 1999;5:320-6.

17. Heath D, Edwards JE. The pathology of hypertensive pulmonary vascular disease: a description of six grades of structural changes in the pulmonary arteries with special reference to congenital cardiac septal defects. Circulation. 1958;18:533-47.

18. Giaid A, Yanagisawa M, Langleben D, Michel R, Levy R, Shennib H, et al. Expression of endothelin-1 in the lungs of patients with pulmonary hypertension. N Engl J Med. 1993;328:1732-9.

19. Hirsch AM, Moser KM, Auger WR, Channick RN, Fedullo PF. Unilateral pulmonary artery thrombotic occlusion: Is distal arteriopathy a consequence? Am J Respir Crit Care Med. 1996;154:491-6.

20. Meyrick B, Reid C. Ultrastructural findings in lung biopsy material from children with congenital heart defects. Am J Pathol. 1980;101:537-42.

21. Hoeper MM, Schwarze M, Ehlerding S, Adler-Schuemeyer A, Spiekerkoetter E, Niedermeyer J, et al. Long-term treatment of primary pulmonary hypertension with aerolized iloprost, a prostacyclin analogue. N Engl J Med. 2000;342:1866-70. 
22. Bradley SP, Auger WR, Moser KM, Fedullo PF, Channick RN, Bloor $\mathrm{CM}$. Right ventricular pathology in chronic pulmonary hypertension. Am J Cardiol. 1996;78:584-7.

23. Archibald CJ, Auger WR, Fedullo PF. Outcome after pulmonary thromboendarterectomy. Semin Thorac Cardiovasc Surg. 1999; 11:164-71.

24. Jamieson SW, Kapalanski DP. Pulmonary endarterectomy. Curr Probl. Surg 2000;37:165-252.

25. Sato TN, Tozawa Y, Deutsch U, Wolburg-Buchholz K, Fujiwara Y, Gendron-Maguire M, et al. Distinct roles of the receptor tyrosine kinases TIE1 and TIE2 in blood vessel formation. Nature. 1995;376:70-4.

26. Davis S, Aldrich TH, Jones PF, Acheson A, Compton DL, Jain V, et al.
Isolation of angiopoietin-1, a ligand for the TIE2 receptor, by secretion-trap expression cloning. Cell. 1996;87:1161-9.

27. Maisonpierre PC, Suri C, Jones PF, Bartunkova S, Wiegand SJ, Radziejewski C, et al. Angiopoietin-2, a natural antagonist for TIE2 that disrupts in vivo angiogenesis. Science. 1997;277:55-60.

28. Valenzuela DM, Griffith JA, Rojas J, Aldrich TH, Jones PF, Zhou H, et al. Angiopoietins 3 and 4: diverging gene counterparts in mice and humans. Proc Natl Acad Sci. 1999;96:1904-9.

29. Davis S, Yancopoulos GD. The angiopoietins: yin and yang in angiogenesis. Curr Top Microbiol Immunol. 1999;237:173-85.

30. Papapetropoulos A, Fulton D, Mahboubi K, Kalb RG, O'Connor DS, Fengzhi L, et al. Angiopoietin-1 inhibits endothelial cell apoptosis via the Akt/survivin pathway. J Biol Chem. 2000;275:9102-5. 